\title{
FUNÇÕES E FORMAÇÃO DO PROFESSOR TUTOR: A ATUAÇÃO DO TUTOR COMO DECISIVA PARA O SUCESSO NO ENSINO SUPERIOR EAD
}

\author{
TERESNA/PI MAIO/2018
}

\author{
Nàdia Cataryna Nogueira e Silva - UNINOVAFAPI - nadiacataryna@uninovafapi.edu.br \\ Maria da Consolação Pitanga de Sousa - UNINOVAFAPI - mpitanga@uninovafapi.edu.br \\ Mônica Fonseca Soares de Carvalho - UNINOVAFAPI - monica@uninovafapi.edu.br
}

Tipo: Relato de Experiência Inovadora (EI)

Categoria: Métodos e Tecnologias

Setor Educacional: EDUCAÇÃO SUPERIOR

\begin{abstract}
RESUMO
O estudo apresenta uma análise sobre as funções e formação necessárias ao professor tutor para atuar nos cursos de graduação Administração, Recursos Humanos e Serviço Social ofertados na modalidade à distância no UNINOVAFAPI. A pesquisa tem caráter descritivo, qualitativo, a partir do relato de experiência sobre o processo de construção do perfil profissional do Professor Tutor do UNINOVAFAPI, por meio de pesquisa documental e a luz do referencial teórico de autores que discutem sobre a temática da EAD, tutoria e formação de professores. Os resultados mostraram que a equipe de tutoria desempenha um papel fundamental no processo de ensino e aprendizagem do programa de EAD da IES, participando ativamente da prática pedagógica, contribuindo para 0 desenvolvimento de acadêmicos, bem como para o acompanhamento e avaliação do projeto pedagógico do curso, da sua execução e da utilização das tecnologias e mídias de apoio. Por fim, conclui-se que; a) Dentre as funções do tutor, a Função principal, está atrelada ao papel de facilitador do processo ensino e aprendizagem, e um dos meios de conseguir este objetivo é através dos recursos pedagógicos que deve ocupar lugar central no planejamento da educação a distância; b) A Formação do tutor deve ser abrangente, orientada, sobretudo, continuada que envolva o conhecimento do processo pedagógico, dos meios tecnológicos e até mesmo a gestão do processo educacional. Deste modo, a participação e influência dos tutores para o sucesso no ensino superior a distância é notável, assim é necessária a criação de um sistema tutorial, apropriado a apoiar e promover 0 desenvolvimento da aprendizagem dos discentes.
\end{abstract}

Palavras-chave: Função; Formação e Professor Tutor. 


\section{1 - Introdução}

A tecnologia da informação através do surgimento da internet veio contribuir em massa para o crescimento da Educação a Distância (EAD). Desta forma, este, foi um dos fatores justificáveis para o alto uso das tecnologias no sistema educacional, assim como, a grande expansão da EAD através de ambientes virtuais. Com isso, novos perfis profissionais surgem, que dentre eles destaca-se o tutor, uma das bases para a construção colaborativa do conhecimento em ambientes virtuais, pois, sua atuação e prática pedagógica são fundamentais para um processo de ensino e aprendizagem efetiva.

Neste sentido, houve uma expansão dos cursos superiores, além dos de pósgraduação, no Brasil, na modalidade EAD. O Estado do Piauí nas últimas décadas vem passando por um processo de desenvolvimento, em especial, na capital, Teresina, a qual vem transformando-se em um centro comercial e de prestação de serviços de referência.

Nesse contexto, com uma marca consolidada, o Centro Universitário UNINOVAFAPI se lança no desafio de agregar à sua reconhecida experiência e competência no ensino presencial (expressa, inclusive, pelo conceito 5 (cinco) obtido na avaliação externa do MEC), a oferta de cursos na modalidade a distância nos níveis de graduação, graduação tecnológica e pós-graduação.

O UNINOVAFAPI é uma Instituição que se articula no cenário de transformações ocasionadas pela emergência de um novo momento histórico caracterizado por uma evolução rápida e contínua da sociedade moderna, especialmente no que se refere ao desenvolvimento das Tecnologias da Informação e Comunicação - TICs, das novas exigências de qualificação profissional, dos novos padrões de organização da educação e, em especial, da exigência do compromisso social das Instituições com a formação de quadros profissionais qualificados para atuarem em um mercado cada vez mais competitivo e globalizado.

A criação dos Cursos a distância na modalidade EAD tiveram como principal objetivo, atender as necessidades e expectativas da população de um ensino de qualidade, sobretudo para atender as novas demandas do mundo do trabalho. O modelo de EAD da Instituição de Ensino Superior (IES) está formatado para atender as diversas necessidades que a implementação dessa modalidade exige.

Os cursos iniciaram em agosto de 2015 e estão ofertados para os polos credenciados; 
UNINOVAFAPI/Teresina, Gilberto Campelo/Teresina e Escola Nossa Senhora da Conceição/Uruçuí com 50 vagas em cada polo.

\section{2 - Objetivos:}

- Analisar as funções desenvolvidas pelo professor tutor nos cursos a distância do UNINOVAFAPI.

- Evidenciar aspectos sobre a formação necessária do professor tutor.

\section{3 - Procedimentos Metodológicos}

A partir dos objetivos, a pesquisa possui uma abordagem qualitativa, de caráter descritivo sobre o relato de experiência a cerca construção do perfil profissional do professor tutor, suas funções e formação necessária para atuar em cursos de graduação na modalidade a distância, à luz do referencial teórico de autores que discutem sobre a temática da $E A D$, tutoria e formação de professores.

Para Severino (2007), os pesquisadores que utilizam os métodos qualitativos buscam explicar o porquê das coisas, exprimindo o que convém ser feito, mas não quantificam os valores e as trocas simbólicas nem se submetem à prova de fatos, pois os dados analisados são não métricos suscitados e de interação e se valem de diferentes abordagens.

Foi investigado o perfil profissional do tutor delineado no período de 2015 à 2017 nos cursos a distância Administração, Gestão de Recursos Humanos e Serviço Social.Os documentos insitucionais utilizados para pesquisa foram o Plano de Gestão, o Projeto Político Pedagógico dos Cursos e Acordo Coletivo (conforme Dissídio Coletivo 2017 organizado pelo Sindicato dos Professores e Auxiliares da Administração Escolar do Estado do Piauí). Para coleta de alguns dados foi obervado, na Plataforma Moodle, o movimento dos tutores no acompanhamento do processo ensino e aprendizagem dos discentes.

\section{4 - Referencial Teórico}

\subsection{O tutor e suas funções para atuação em cursos na modalidade EAD}

A expressão tutor por si só dá uma conotação de "cuidar", "tutela" de acordo com Aretio (1996) "a palavra tutor leva implícita a figura jurídica pela qual a lei outorga a proteção, a tutela, defesa ou proteção de uma pessoa menor ou necessitada, em sua 
primeira acepção". Assim, na EAD, o tutor deve ser a pessoa que irá intermediar o conhecimento ao aluno, a "imagem de uma pessoa que dá assistência no estudo em sentido mais restrito". (PETERS, 2001, P. 58). De acordo com Sá:

A tutoria como método nasceu no século XV na universidade, onde foi usada como orientação de caráter religioso aos estudantes, com o objetivo de infundir a fé e a conduta moral. Posteriormente, no século XX, o tutor assumiu $O$ papel de orientador e acompanhante dos trabalhos acadêmicos, e é com este mesmo sentido que incorporou aos atuais programas de educação à distância. (SÁ,1988, p. 7).

Portanto, o tutor além de conhecer o conteúdo que será ministrado, a tecnologia e recursos tecnológicos utilizados e os meios de interação disponíveis por estes, deverá mobilizar a comunidade tanto em torno do aprendizado individual, como também da coresponsabilidade do aprendizado em grupo, estando atento às diferenças individuais e planejando a estrutura de aula, em que o aluno possa relacionar o conteúdo que está sendo ministrado às suas experiências, será basicamente um "termômetro" da aprendizagem do alunado.

Aretio (2001) coloca três tipos de funções assumidas pelo tutor, que são: A função acadêmica, ligada ao aspecto cognitivo, relacionada à transmissão do conteúdo, à transposição didática, ao esclarecimento das dúvidas dos alunos; A função institucional, relacionada aos procedimentos administrativos e à própria formação acadêmica do tutor; e A função orientadora, centrada em aspectos afetivos e motivacionais do aluno.

O professor tutor tem um papel de "parceiro dos estudantes no processo de construção do conhecimento. Ele orienta o aluno em seus estudos relativos à disciplina pela qual é responsável, esclarece dúvidas e explica questões relativas aos conteúdos da disciplina; em geral participa das atividades de avaliação." Segundo autor Belloni (2001), são poucos os estudos já existentes sobre as competências do tutor ou "professor coletivo". Até porque "ensinar não é transmitir conhecimento, mas criar as possibilidades para a sua própria produção ou a sua construção" (FREIRE, 1998, p.52).

Assim, o tutor deve atuar juntamente ao professor conteudista e deve ter quase as mesmas competências para atuar detendo-se de domínio completo do conteúdo para que o acompanhamento do aluno seja consistente e bem pautado.

Há uma grande diferença entre o docente e o tutor, e estas continuam sendo confundidas, e tidas como semelhantes. Esta diferença consiste na prática pedagógica de ambos, ou seja, nas intervenções do tutor na EAD, Litwin (2001, p.102), caracteriza bem a atuação do tutor dentro de três dimensões, que são: 
1. Tempo - o tutor deverá ter a habilidade de aproveitar bem seu tempo, sempre escasso. Ao contrário do docente, o tutor não sabe se o aluno assistirá à próxima tutoria ou se voltará a entrar em contato para consultá-lo; por esse motivo aumentam o compromisso e o risco da sua tarefa;

2. Oportunidade - em uma situação presencial, o docente sabe que o aluno retornará; que caso este não encontre uma resposta que o satisfaça, perguntará de novo ao docente ou a seus colegas. Entretanto, o tutor não tem essa certeza. Tem de oferecer a resposta específica quando tem a oportunidade de fazer isso, porque não sabe se voltará a ter;

3. Risco - aparece como consequência de privilegiar a dimensão tempo e de não aproveitar as oportunidades. O risco consiste em permitir que os alunos sigam com uma compreensão parcial, que pode se converter em uma construção errônea sem que o tutor tenha a oportunidade de adverti-lo. "O tutor deve aproveitar a oportunidade para o aprofundamento do tema e promover processos de reconstrução, começando por assinalar uma contradição".

O tutor, na nova sociedade, "sociedade do conhecimento", revê todo o seu modo crítico, o seu papel de parceiro, interlocutor, orientador do educando na busca de suas aprendizagens, torna-se o aprendiz, estuda, pesquisa, debate, discute, constrói e produz conhecimento, desenvolvendo habilidades e atitudes, tudo ao mesmo tempo em que atua.

\subsection{Formação do tutor para atuar na modalidade EaD}

A formação do tutor é uma das principais características para sua atuação na modalidade $E A D$, pois em sua maioria são formados no ensino presencial e não possui experiência como cursista na modalidade EAD. Sendo assim, é necessário que este tutor antes de exercer a tutoria seja capacitado, deverá receber um treinamento, sobre o material didático, as práticas pedagógicas voltadas para a modalidade, que conheçam todos e saiba como utilizar pedagogicamente todos os recursos disponíveis na plataforma virtual ou usados no processo ensino e aprendizagem.

De acordo com os Referenciais de qualidade para educação superior a distância, considerando a especificidade do seu papel enquanto mediador do processo pedagógico:

(...) o tutor deve ser compreendido como um dos sujeitos que participa ativamente da prática pedagógica. Suas atividades desenvolvidas a distância e (ou) presencialmente devem contribuir para o desenvolvimento dos 
processos de ensino e de aprendizagem e para o acompanhamento e avaliação do projeto pedagógico. (BRASIL, 2007, p. 21).

Um dos grandes desafios considerados é quanto ao oferecimento de cursos que utilizem recursos tecnológicos de informação e comunicação avançados e que garantam o tutor demonstrar ao alunado o processo de auto-aprendizagem, necessário a modalidade $E A D$, a partir da utilização de estratégias pedagógicas bem delineadas e refletidas. Para isso, é necessária uma boa capacitação do tutor e que este possa atender as expectativas dos alunos.

\section{5 - Apresentação e Discussão dos Resultados}

A tutoria (mentoring) para EAD, no entendimento do UNINOVAFAPI, é um método interativo de acompanhamento pedagógico utilizado para orientar e tirar dúvidas dos alunos durante o desenvolvimento de atividades acadêmicas síncronas e assíncronas. $A$ equipe de tutoria da IES acompanha e comunica-se contínua e sistematicamente com os alunos, planejando, dentre outras coisas, o desenvolvimento do seu estudo e contribuindo para a resolutividade das dúvidas e problemas que possam ocorrer durante o processo.

O Plano de Gestão em EaD UNINOVAFAPI, traz a metodologia adotada para o curso de graduação na modalidade EAD que está apoiada na utilização de mídias complementares entre si. As atividades são desenvolvidas através de recursos didáticos como: módulos impressos por áreas de conhecimento, ou por disciplina, livro didático, estes serão entregues aos cursistas, utilizados também recursos pedagógicos do Ambiente Virtual (AVA) Plataforma Moodle, aulas ao vivo via satélite, assim, como aulas narradas, disponibilizados no ambiente.

Concomimentante ao Plano de Gestão, o Projeto Político Pedagógico dos Cursos de graduação EAD, definem que além dos módulos impressos, para melhor interatividade, as aulas, ainda contam com encontros presenciais, e atividaades complementares tais como, grupos de estudos (GE) a distância, monitoria e um sistema de acompanhamento ao estudante, através de acompanhamento local (professor tutor presencial) e a distância (professor tutor a distância).

Para maior suporte o curso tem o professor autor, que elabora o material didático impresso, e o professor da disciplina, que acompanha a aplicação deste material nos Polos de apoio presencial, plataforma virtual e intervém no desenvolvimento das atividades tais como: participação nos fóruns, envio de mensagens, feedback dirigido, 
entre outros.

Conforme o Acordo Coletivo estabelecido entre o UNINOVAFAPI e o Sindicato dos Professores do Piauí, à nomenclatura "Professor Tutor" foi adotada na IES. O Acordo é renovado a cada dois anos, entre as partes, onde são revisados os artigos e ajustados caso necessário. As funções e formação do Professor Tutor estão fundamentadas no Acordo Coletivo e considerando a análise de artigos sobre a temática da tutoria.

As funções foram classificadas nos âmbitos: a) Conhecimento da área de atuação (fundamentos da EAD, uso de tecnologias); b) Comunicação com os acadêmicos pelos diversos meios de interação; c) Ter atitude, iniciativa, mobilizando os alunos a paticipar do curso; d) Ensino e aprendizagem, auxiliando os alunos a resolver questões pedagógicas, sobretudo, fazer intervenções didáticas.

Quanto ao processo de formação dos tutores, no UNINOVAFAPI, está orgnizado em três momentos. No primeiro momento, são apresentadas as atribuições, as competência e habilidades esperadas no desenvolvimento das atividades. No segundo momento, é realizada a capacitação no uso de recursos e ferramentos da Sala de Aula Virtual Plataforma Moodle.

E o terceiro, consiste no curso "Docência e Tutoria" que visa capacitar os docentes, professores tutores e colaboradores para atuar em cursos online. O curso é realizado na modalidade a distância "e-larning", o que significa que todo o material didático bem como atividades de fixação de conteúdo são desenvolvidos de forma assíncrona.

Como abordagens específicas, o curso tem como objetivos: discutir acerca do contexto da EAD, docência e a mediação em ambientes online (o papel do professor tutor presencial e online) e compreender as estratégias de avaliação para Educação online. No UNINOVAFAPI, a formação do tutor é contínua, pois ao longo dos semestres são relaizadas reuniões pedagógicas para avaliar as atividades refletindo sobre as possíeveis fragilidades identificadas.

A equipe de tutoria do UNINOVAFAPI oferece tutoria a distância e presencial, de forma integrada, privilegiando a interatividade e o trabalho colaborativo. A tutoria a distância atua a partir do Núcleo de Educação a Distância NEAD, mediando o processo pedagógico com estudantes temporal e/ou geograficamente distantes, vinculados aos polos de apoio presencial credenciados. A tutoria presencial é realizada nos polos de apoio presencial, através de um tutor local em cada sala de aula, que acompanha os estudantes em todas as atividades acadêmicas presenciais realizadas. 


\section{Considerações Finais}

Com o advindo da Educação a Distância surge o profissional tutor, que irá atuar de forma direta com o aluno, criando assim um ambiente escolar, auxiliando principalmente os que apresentam maior dificuldade com a tecnologia e estimular os alunos a desenvolverem sua autonomia educacional.

Para que este processo seja satisfatório faz- se necessário profissionais tutores com funções definidas e uma formação adequada, que estejam sempre dispostos a qualificarse, ter domínio dos conteúdos que irá tutorar e como tal, deverá estar sempre pronto a esclarecer as dúvidas dos alunos, assim como na educação presencial deverá desenvolver técnicas comuns a educação mas que não podem ser dispensadas, tais como planejamento e avaliação.

A Função principal do tutor, portanto, significa facilitador do processo ensino e aprendizagem. Dessa forma, um dos meios de conseguir este objetivo é através dos recursos pedagógicos. A utilização pedagógica destes recursos deve ocupar lugar central no processo de planejamento da educação a distância, bem como a interação que o tutor irá propiciar a partir delas, respondendo a necessidades educacionais a serem atendidas.

As alternativas de efetivação da relação pedagógica são critérios que deve presidir a escolha dos meios, o modo de produzir materiais, a organização da veiculação e dos canais de comunicação a distância entre professores e discentes durante todo o processo.

Como os desafios de quem atua nesta modalidade é grande, a Formação do tutor, deve ser abrangente, orientada e continuada que envolva o conhecimento do processo pedagógico, a seleção e adequação da proposta de curso ou disciplina às especificidades dos meios tecnológicos envolvidos, também a gestão do processo educacional em rede; e a produção de materiais didáticos e comunicativos; orientações pedagógicas e estratégias para atuarem com os alunos, a fazerem com que estes permaneçam estudando, dentre muitas outras características.

Os resultados mostraram que os professores tutores desempenham um papel fundamental no processo de ensino e aprendizagem dos discentes, participando ativamente da prática pedagógica, contribuindo para o desenvolvimento do acadêmico, bem como para o acompanhamento e avaliação do projeto pedagógico do curso, da sua execução e da utilização das tecnologias e mídias de apoio. 
Podemos identificar que a participação e influência dos tutores para o sucesso dos cursos é notável, pois este deve conduzir o aluno de forma autônoma ao conhecimento. Assim, para que um curso de EAD tenha sucesso, é necessária a criação de um sistema tutorial, apropriado a apoiar e promover o desenvolvimento da aprendizagem dos acadêmicos.

Algumas especificidades do aluno na modalidade EAD não diferem muito do presencial, pois estes procuram mediar, interagir, relacionar, integrar equipamentos para chegar ao processo ensino e aprendizagem, satisfazendo a necessidade do aprendiz, alcançando os objetivos propostos. Silva (2014) destaca que o aluno na modalidade EAD, deverá ter capacidade de se adaptar a um ambiente que se modifica rapidamente, aprendendo novos conhecimentos e assimilando-os, sabendo trabalhar em grupo colaborativo, sendo independente, tomando iniciativa, sabendo identificar e solucionar problemas.

A relação do tutor com o aluno deve estar pautada em critérios numa perspectivas humana, social, política, laboral, tecnológica, sob uma visão axiológica, ética e crítica da sociedade. Essa inter-relação para que ocorra possui rotineiros desafios a serem superados, desde o acesso do aluno a plataforma a adaptação das atividades semanais à plataforma virtual.

\section{Referências}

ARETIO, Lourenzo García. La educación a distancia y la UNED. Madrid: UNED, 1996.

BELLONI, M. L. Educação a distância. Campinas, SP: Autores Associados, 1999

FREIRE, Paulo. Pedagogia da Autonomia: saberes necessários à prática educativa. São Paulo:Paz e Terra, 1996.

LITWIN, Edith (org). Educação a Distância: Temas para Debate de uma Nova Agenda Educativa. Porto Alegre, Artmed, 2001.

MARCONI, M.A; LAKATOS, E.M. Técnicas de pesquisa: planejamento e execução de pesquisas, amostragens e técnicas de pesquisas, elaboração, análise e interpretação de dados. 4. ed. São Paulo: Atlas, 1999

PETERS, Otto. Didática do ensino a distância: experiências e estágio da discussão numa visão internacional. São Leopoldo: UNISINOS, 2001. 
PROJETO INSTITUCIONAL PARA EDUCAÇÃO A DISTÂNCIA:Plano de Gestão. Teresina: UNINOVAFAPI, 2012.

SEVERINO, Antonio Joaquim. Metodologia do trabalho científico. 23 ed. São Paulo: Cortez, 2007.

SILVA, Siony da. TECNOLOGIAS DE INFORMAÇÃO E COMUNICAÇÃO E A EaD.Artigo publicado na Revista Sinergia (CEFETSP), v. 5, p. 48-51, 2004. 